sleep disturbances in patients with rheumatoid arthritis-design of a randomized controlled trial. BMC musculoskeletal disorders. 2014;15(1):4

Disclosure of Interests: None declared

DOI: 10.1136/annrheumdis-2020-eular.2135

\section{AB1307-HPR INVESTIGATION OF THE EFFECTIVENESS OF TAI CHI EXERCISE PROGRAM ON CARDIOPULMONARY FUNCTIONS AND QUALITY OF LIFE IN PATIENTS WITH SYSTEMIC SCLEROSIS}

\section{S. Y. Cetin ${ }^{1}$, B. Basakci Calik ${ }^{2}$, A. Ayan ${ }^{3} .{ }^{1}$ Akdeniz University, Department} of Physiotherapy and Rehabilitation, Antalya, Turkey; ${ }^{2}$ Pamukkale University, Physiotherapy, Denizli, Turkey; ${ }^{3}$ Antalya Training and Research Hospital, Rheumatology, Antalya, Turkey

Background: Systemic sclerosis (SSc) is an autoimmune disease that not only affects the skin but also causes symptoms that involve important internal organs such as joints, muscles, and heart and lungs. Due to all these multiple system involvements, the quality of life of individuals with scleroderma decreases. Tai Chi Chuan is a combination of physical exercise and relaxation techniques, and it is a traditional Chinese exercise method used to improve mental and physical health of people. There are many studies showing that Tai Chi improves the body's aerobic capacity and psychological well-being. In the literature, Tai Chi has been shown to reduce pain, improve physical function, improve healing effects on depression and quality of life, especially, in the elderly, individuals with musculoskeletal diseases such as rheumatoid arthritis and osteoarthritis, and improve cardiac vascular risk factors such as hypertension and diabetes.

Objectives: The aim of the study is to examine the effectiveness of Tai Chi on cardiopulmonary functions and quality of life in patients with SSc.

Methods: 28 SSc patients ( 25 females, 3 males) with an average age of 53.00 \pm 10.00 were included in the study. For training, patients were divided into two groups by block randomization method. Group 1 received 60 minutes of Tai Chi exercise program and Group 2 received 60 minutes of home exercise for 2 days a week for 8 weeks. 6-min walk test (6MWT) and St. George Respiratory Questionnaire was used to evaluate the cardiopulmonary functions, Short form 36 (SF-36) was used to evaluate the quality of life. All evaluations were performed at baseline and at the end of the 8th week

Results: When the groups were compared before training, there was no significant difference $(p>0.05)$. In post-training comparisons, there was a significant difference in all parameters in Tai Chi group ( $p$ : 0.001-0.045); there was a significant difference in the physical function sub-parameter of SF-36 and 6MWT in the home exercise group (p: 0.045, p: 0.038, respectively). Comparing the post-training groups, Tai Chi group was found to be superior in terms of all parameters compared to the home exercise group ( $p$ : 0.00-0.04). No side effects were observed during the exercises.

Conclusion: As a result of our study; Tai Chi has a possitive effect on cardiopulmonery function and quality of life in patients with SS. Tai Chi should be included in rehabilitation programs as a safe alternative type of exercise to improve cardiopulmonery function and quality of life in patients with SSc.

References:

[1] de Oliveira NC, Portes LA, Pettersson H, Alexanderson H, Boström C. Aerobic and resistance exercise in systemic sclerosis: State of the art. Musculoskeletal Care. 2017;15:316-323.

[2] Jia X, Jiang C, Tao J, Li Y, Zhou Y, Chen LD. Effects of core strength training combined with Tai Chi Chuan for the musculoskeletal system and cardiopulmonary function in older adults: A study protocol for a randomized controlled trial. Medicine (Baltimore). 2018;97(35):e12024.

[3] Wang C, Schmid CH, Hibberd PL, Kalish R, Roubenoff R, Rones R, McAlindon T. Tai Chi is effective in treating knee osteoarthritis: a randomized controlled trial. Arthritis Rheum. 2009; 61:1545-1553.

[4] Wang C, Roubenoff R, Lau J, Kalish R, Schmid CH, Tighiouart H, Rones R, Hibberd PL Effect of Tai Chi in adults with rheumatoid arthritis. Rheumatology (Oxford) 2005; 44:685-687.

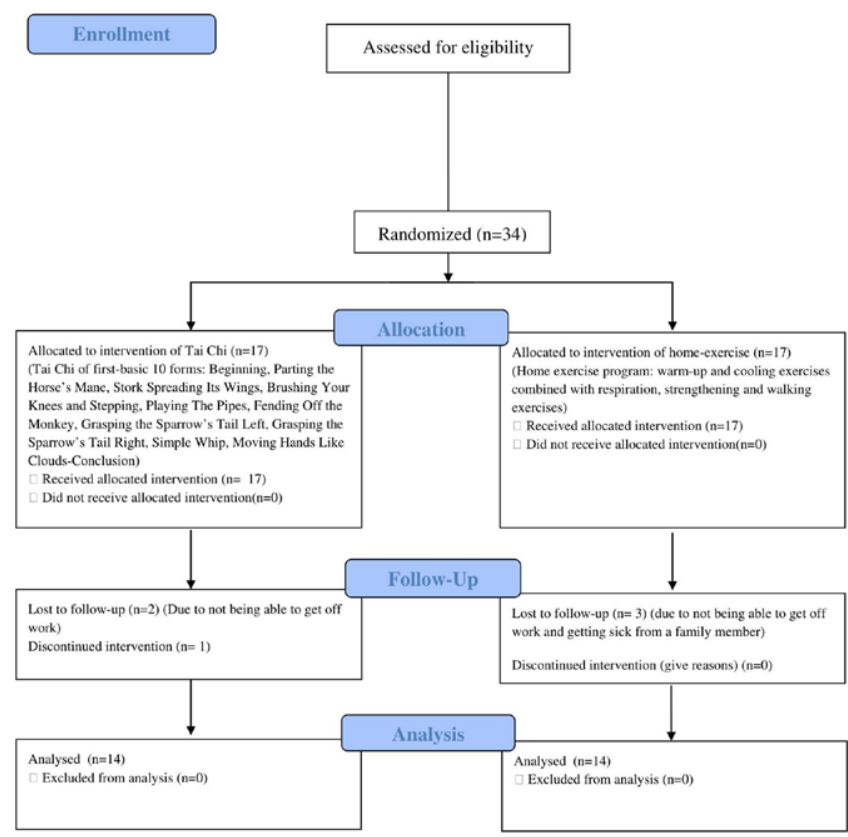

Figure1. Flow chart of the progress through the phases of the study

Disclosure of Interests: None declared

DOI: 10.1136/annrheumdis-2020-eular.5201

\section{AB1308-HPR DEVELOPMENT OF AN E-LEARNING PATIENT EDUCATION PROGRAM TARGETING PATIENTS WITH RHEUMATOID ARTHRITIS: FROM CONTENT TO DESIGN}

L. Raunsbæk Knudsen ${ }^{1}$, K. Lomborg ${ }^{2,3}$, A. De Thurah ${ }^{1,3},{ }^{1}$ Aarhus University Hospital, Department of Rheumatology, Aarhus N, Denmark; ${ }^{2}$ Steno Diabetes Center Copenhagen, Copenhagen, Denmark; ${ }^{3}$ Aarhus University, Department of Clinical Medicine, Aarhus, Denmark

Background: Patient education (PE), with the aim of supporting patients to self-manage their disease is important in the treatment and care of patients with rheumatoid arthritis (RA) (1). Today, there is a shift in the organization of healthcare systems due to a demographic change towards ageing populations and an increasing use of technology. Advancements in web-technology can offer alternative ways to provide PE - e.g. through an e-learning platform. However, E-Learning development must be based on the needs of the learners and on existing evidence on both education and content.

Objectives: To develop an e-learning platform targeting newly diagnosed patients with RA.

Methods: Focus group interviews with patients, rheumatologists and nurses, with the aim of exploring informational and educational needs related to RA and how this may be communicated in an e-learning program, were conducted. We used a short interview guide to ensure the focus of the interviews, however, strived for a less structured start of the interview to promote a free discussion and later a more structured discussion of specific questions. Pictures, illustrating possible topics in PE within RA and ways to communicate, were also applied. The transcribed interviews were analyzed using thematic analysis (2).

The theoretical framework in the development and design drew on the cognitive theory of multimedia learning (3) and entertainment education (4).

Results: Four themes, covering experiences and needs emerged in the analysis of the focus-group interviews; 'Knowledge of RA, the disease course and prognosis,' 'Medical treatment', $A$ new life situation' and 'Daily living with RA'.

Subsequently, the program was developed through an iterative process between the project group, patient representatives, a communication consultant, graphic designers and an e-learning company.

The program was divided into three learning modules covering knowledge of RA, complications, medical treatment, examinations and daily living with RA, e.g. coping with emotions, pain, fatigue, work, education, physical activity etc. It offers 
a combination of e.g. animations, videos with personal patient stories, podcasts, written text, spoken words and interactive quizzes.

Conclusion: The e-learning program is developed and ready for feasibility testing. Subsequently, the effectiveness of the program will be tested in a RCT study among approximately 250 patients.

References:

[1] Zangi HA, Ndosi M, Adams J, et al. EULAR recommendations for patient education for people with inflammatory arthritis. Ann Rheum Dis. 2015; 0:1-9.

[2] Braun V, Clarke V. Using thematic analysis in psychology. Qualitative research in psychology. 2006; 3 (2): 77-101.

[3] Mayer R. The Cambridge handbook of multimedia learning. 2005. New York.

[4] Singhal A, Cody MJ, Rogers EM, Sabido M (editors). Entertainment-education and social change - History, research and practice. Taylor and Francis; 2003.

Acknowledgments: We thank the participants in focus groups who shared their experiences. We also express our gratitude to the Novo Nordisk Foundation for supporting the study. Furthermore, we are grateful for the collaboration with the communication consultants, graphic designers and the e-learning company, who have contributed to the development of the e-learning platform.

Disclosure of Interests: Line Raunsbæk Knudsen Consultant of: Phizer (Not relevant for the present study)., Speakers bureau: Phizer (Not relevant for the present study).

Lily (Not relevant for the present study).

Roche (Not relevant for the present study)., Kirsten Lomborg: None declared Annette de Thurah Grant/research support from: Novartis (not relevant for the present study)., Speakers bureau: Lily (not relevant for the present study). DOI: 10.1136/annrheumdis-2020-eular.2280

\section{AB1309-HPR EFFICACY OF ADDING CAFFEINE TO THE TREATMENT REGIMEN IN REDUCING METHOTREXATE INTOLERANCE IN PATIENTS WITH RHEUMATOID ARTHRITIS: A RANDOMIZED CONTROLLED STUDY}

A. Fehr ${ }^{1}$, F. El Noby ${ }^{2}$, N. Fathi ${ }^{3}$, R. Lotfy ${ }^{2} .{ }^{1}$ Faculty of Medicine, Helwan University, Rheumatology \& Physical Medicine Department, Helwan, Egypt; ${ }^{2}$ Faculty of Medicine, Aswan University, Rheumatology Department, Aswan, Egypt; ${ }^{3}$ Assuit Faculty of Medicine, Assuit, Egypt

Background: Rheumatoid arthritis is one of common form of chronic inflammatory arthritis. Methotrexate has remained anchor treatment because of its potent efficacy ${ }^{1}$. Intolerance to Methotrexate is a common cause of non-compliance ${ }^{2 \& 3}$. Objectives: To investigate the effect of adding caffeine orally as Methylxanthines (Caffeine), act as adenosine receptor antagonists ${ }^{4}$ to reduce symptoms of moderate to severe methotrexate intolerance in patients with Rheumatoid Arthritis ${ }^{5}$. Methods: A prospective, randomized controlled study conducted at Aswan University Hospital, Egypt from Jan 2018 till may 2019. Sixty patients with Rheumatoid arthritis who have had experienced moderate to severe methotrexate intolerance was enrolled in the study. The methotrexate intolerance severity score (MISS) ${ }^{6}$ was evaluated at base line before initiation of study then at the next three months consecutively. Patients were randomly assigned by closed envelope method into 2 groups each containing 30 patients: Group (A); 30 patients was prescribed caffeine (coffee or dark chocolate) as an antidote to methotrexate intolerance $^{7}$. Group (B); 30 matched patients acted as control group that included who will continue methotrexate regimen without addition of any extra caffeine.

Results: Twenty four patients $(80 \%)$ at time three follow up visit showed full improvement of symptoms of methotrexate-intolerance compared to ten patients (33.3\%) at 2nd month follow up visit and seven patients (23\%) at 1st month follow up visit with statistically significant difference all over the study period $(\mathrm{P}=0.005)$. half of study group patients discontinued anti-emetic and other drugs while none in control group did.

Conclusion: Adding caffeine to management regimen can reduce the symptoms of severe methotrexate-intolerance in Rheumatoid Arthritis patients.

References:

[1] Friedman, B., \& Cronstein, B. (2019). Methotrexate Mechanism in Treatment of Rheumatoid Arthritis. Joint Bone Spine, 86(3):301-307

[2] Wang, W., Zhou, H., \& Liu, L. (2018). Side effects of methotrexate therapy for rheumatoid arthritis: a systematic review. European journal of medicinal chemistry. Volume 158, 502-516

[3] Bulatović, M., Heijstek, M. W., Verkaaik, M., van Dijkhuizen, E. P., Armbrust, W., Hoppenreijs, E. P., ... \& Rademaker, C. M. (2011). High prevalence of methotrexate intolerance in juvenile idiopathic arthritis: development and validation of a methotrexate intolerance severity score. Arthritis \& Rheumatism, 63(7), 2007-2013.

[4] Malaviya, A., Baghel, S., Verma, S., Thakran, R., \& Messi, C. (2019). Use of coffee for alleviating methotrexate intolerance in rheumatic diseases. Indian Journal of Rheumatology, 14(1), 79-79.

[5] Ribeiro, J. A., \& Sebastiao, A. M. (2010). Caffeine and adenosine. Journal of Alzheimer's Disease, 20(s1), S3-S15.

[6] Fatimah, N., Salim, B., Nasim, A., Hussain, K., Gul, H., \& Niazi, S. (2016). Frequency of methotrexate intolerance in rheumatoid arthritis patients using methotrexate intolerance severity score (MISS questionnaire). Clinical rheumatology, 35(5), 1341-1345.

[7] Malaviya, A. N. (2017). Methotrexate intolerance in the treatment of rheumatoid arthritis (RA): effect of adding caffeine to the management regimen. Clinical rheumatology, 36(2), 279-285.

Disclosure of Interests: None declared

DOI: 10.1136/annrheumdis-2020-eular.1887

\section{AB1310-HPR EFFECTS OF INSTRUMENT-ASSISTED SOFT TISSUE MOBILIZATION ON FROZEN SHOULDER: A RANDOMIZED CONTROLLED TRIAL}

E. Kaya Mutlu ${ }^{1}$, T. Birinci ${ }^{2}$, S. Kılıc ${ }^{3} .{ }^{1}$ Istanbul University-Cerrahpasa, Department of Physiotherapy and Rehabilitation, Istanbul, Turkey; ${ }^{2}$ Istanbul Medeniyet University, Department of Physiotherapy and Rehabilitation, Istanbul, Turkey; ${ }^{3}$ Istanbul Aydın University, Institute of Health Sciences, Istanbul, Turkey

Background: Frozen shoulder has a greater incidence, more severe course, and resistance to treatment in patients. Management is based on the underlying cause of pain and stiffness. Joint mobilization has been reported to improve joint range of motion in frozen shoulder. However, there is no information regarding the effect of instrument-assisted soft tissue mobilization (IASTM) in frozen shoulder. We proposed that there would be no significant difference between the two manual physical therapy techniques with relatively similar treatment effects in the frozen shoulder.

Objectives: The aim of this randomized controlled study was to compare the effectiveness of IASTM and joint mobilization in the treatment of patients with frozen shoulder.

Methods: Thirty patients with phase II frozen shoulder (mean age 50,9 years, age range 39-65 years) were randomly assigned to one of the two treatment groups: Group I received joint mobilization combined with manual stretching exercise and Group II received IASTM with manual stretching exercise (two days per week for six weeks) (Figure 1). The pain level was evaluated with a visual analogue scale (VAS) and the active range of motion (ROM) was measured with a universal goniometer. The Disabilities of the Arm, Shoulder and Hand score and the Constant-Murley score were used for functional assessment. The assessments were performed at baseline and after the 6-week intervention.

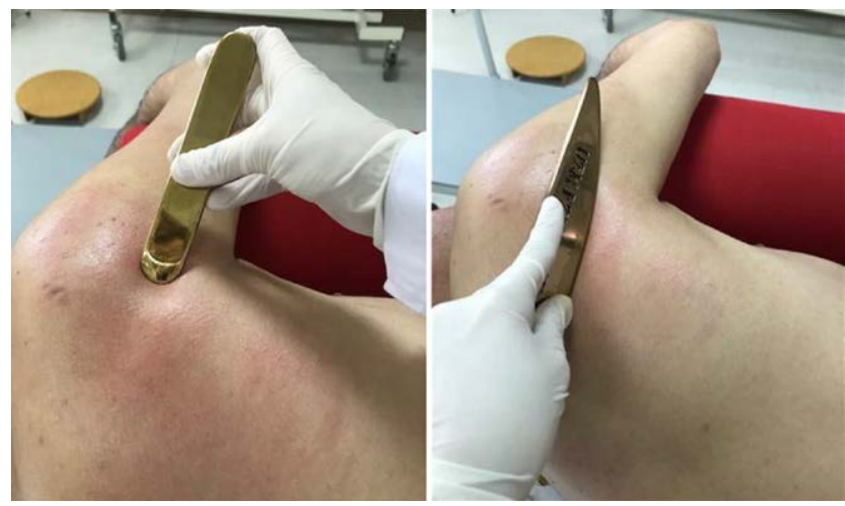

Figure 1. Instrument-Assisted Soft Tissue Mobilization

Results: Both groups had a significant decrease in pain according to VAS and a significant increase in ROM and function level $(p<0.05)$. After the 6-week intervention, improvement of shoulder abduction ROM in Group I was found significantly higher than Group II ( $p=0.01)$, on the other hand, Constant-Murley score in Group II was found significantly higher compared to Group I ( $p=0,001)$.

Conclusion: Our results supported the hypothesis that either joint mobilization or IASTM, performed in addition to stretching exercise, provided similar improvements in pain levels in patients with the frozen shoulder.

References:

[1] Kelley MJ, Shaffer MA, Kuhn JE, Michener LA, Seitz AL, Uhl TL, et al. Shoulder Pain and Mobility Deficits: Adhesive Capsulitis, J Orthop Sports Phys Ther, 2013:43:1-31.

[2] Celik D, Kaya Mutlu E. Does Adding Mobilization to Stretching Improve Outcomes for People with Frozen Shoulder? A Randomized Controlled Clinical Trial, Clin Rehab, 2016: 30(8): 786-794.

[3] Iked N, Otsuka S, Kawanishi Y, Kawakami Y. Effects of Instrument-Assisted Soft Tissue Mobilization on Musculoskeletal Properties, Med Sci Sports Exerc, 2019:51(10): 2166-2172.

Disclosure of Interests: None declared

DOI: 10.1136/annrheumdis-2020-eular.6151 